\title{
PROTOTYPE KNOWLEDGE MANAGEMENT SYSTEM UNTUK MENINGKATKAN PENYULUHAN KELUARGA BERENCANA BERBASIS ANDROID:STUDI KASUS BADAN PEMBERDAYAAN PEREMPUAN PERLINDUNGAN ANAK DAN KELUARGA BERENCANA KOTA BEKASI
}

\author{
Nurdiana Handayani ${ }^{1}$ \\ 1) Universitas Muhammadiyah Tangerang / Fakultas Teknik, \\ Program Studi Informatika \\ JI. Perintis Kemerdekaan 1/33 Cikokol Kota Tangerang TLP. 55793251, 55772949, 55793802, 55736926 \\ e-mail: dieyan3@gmail.com
}

\begin{abstract}
The management of knowledge (knowledge management) is very important in an institution or organization to acquire and share knowledge (knowledge sharing) in order to develop the human resource potential and manage the company's assets or intellectual institutions, thus becoming close attention of Badan Pemberdayaan Perempuan, Perlindungan Anak dan Keluarga Berencana (BP3AKB) Bekasi. The purpose of this study was to determine the extent of the influence of the knowledge management system of knowledge in the KB extension outreach activities, and building a knowledge management system application that can assist employees in planning extension activities online that can be accessed by android smartphone, which is expected to increase the productivity of employees. The method of this research is descriptive quantitative method which is supported by The Most Admired Knowledge Enterprise (MAKE), and a model of knowledge management system knowledge management system architecture using Amrit Tiwana. The results of this study based on questionnaires to the application of the android-based knowledge management system for employees that are on the 3:40 to 4:19 interval, the average value of the entire statement at 4:00 is well received.
\end{abstract}

Keywords: Knowledge Management, Activity Counseling KB, MAKE, Architecture Knowledge Managemet System Amrit Tiwana, Android application.

\section{PENDAHULUAN}

\section{Latar Belakang Masalah}

Sumber daya manusia (SDM) merupakan salah satu faktor yang sangat penting bagi organisasi dalam melaksanakan proses knowledge management untuk mengembangkan potensi SDM dan mengelola asset perusahaan/lembaga yang bersifat intelektual. Menurut Andy, Sugiarto dan Hetharia (2011) bahwa Knowledge management merupakan salah satu cara untuk mengidentifikasi, memilih, mengatur, dan menyebarkan informasi serta keahlian penting di dalam suatu organisasi sebagai upaya untuk mengembangkan produktivitas dan prestasi kerja sehingga mampu meningkatkan daya saing organisasi tersebut.

Teknologi informasi terus berkembang dengan pesat adalah mobile phone. Dahulu mobile phone hanya bisa digunakan untuk komunikasi suara antar manusia. Tetapi sekarang kemampuan mobile phone sudah sangat canggih, dimana yang dulunya hanya bisa dilakukan oleh komputer sekarang dapat dilakukan oleh mobile phone. Mobile phone jenis ini dikenal oleh masyarakat luas dengan sebutan smartphone. 
Salah satu sistem operasi mobile yang digunakan oleh smartphone adalah Android. Android adalah sebuah sistem operasi untuk smartphone berbasis linux. Salah satu kelebihan Android dibanding sistem operasi smartphone lainnya adalah Android bersifat open source code sehingga orang-orang dapat mengkustomasi fitur-fitur yang belum ada di sistem operasi Android sesuai dengan keinginan mereka,

Perkembangan dan penguasaan teknologi telah memaksa kompetisi pegawai/kader penyuluh di Badan Pemberdayaan Perempuan Perlindungan Anak dan Keluarga Berencana (BP3AKB) untuk meningatkan penyuluhan sehingga informasi yang disampaikan sesuai yang diharapkan. BP3AKB mempunyai tugas pokok melaksanakan penyusunan dan pelaksanaan kebijakan daerah di bidang keluarga berencana khususnya. Pada BP3AKB budaya berbagi pengetahuan sudah berjalan namun kurang efektif karena belum adanya perangkat pendukung untuk pengembangan knowledge management system yang baik. Dimana penyebaran pengetahuan belum rata dan pengelolaan pengetahuan masih bersifat manual. Salah satu strategi yang dapat ditempuh untuk meningkatkan produktivitas pegawai dalam bidang penyuluhan secara berkelanjutan dapat dilakukan dengan penerapan Knowledge Sharing dengan aplikasi KMS berbasis android.

Prinsip saling tukar pengetahuan (knowledge sharing) seperti diungkapkan oleh Bommen dan Bechina (2006) adalah mentransfer pengetahuan kepada orang lain. Antara seseorang yang satu dengan yang lain dapat saling bertukar pengetahuan yang berasal dari pengalaman mereka masing-masing. Penjelasan tersebut dapat diaplikasikan dalam proses pembekalan penyuluhan yaitu pegawai/kader penyuluh yang tahu menyampaikan apa yang tidak diketahui pegawai/kader yang lainnya sedangkan pegawai/kader yang tidak tahu berusaha mencari tahu pada pegawai/kader penyuluh yang lebih tahu agar dapat memecahkan suatu permasalahan yang timbul pada proses penyuluhan. Apalagi selama ini setiap informasi dan dokumentasi diorganisasi tidak disimpan dengan baik, sehingga apabila ada permasalahan, pegawai/kader penyuluhan akan sulit mencari solusinya.

Penerapan berbagi pengetahuan berbasis smartphone Android memberikan kemudahan kepada para pegawai/kader BP3AKB untuk belajar pemahaman tentang penyuluhan dan berbagi pengetahuan kapanpun dan dimanapun. Sehingga diharapkan pengetahuan pegawai/kader penyuluh dapat meningkat.

\section{Batasan Masalah}

Dalam penelitian ini hanya membahas bagaimana berbagi pengetahuan (knowledge sharing) antara pegawai/kader yang didukung dengan aplikasi berbasis android pada Badan Pemberdayaan Perempuan, Perlindungan Anak dan Keluarga Berencana. Aplikasi KMS berbasis Android juga menghasilkan informasi untuk saling berdiskusi melalui forum, download panduan diktat dan Materi, menginput laporan dan pengetahuan lainnya.

\section{Perumusan Masalah}

Berdasarkan identifikasi masalah dan batasan masalah, maka rumusan masalah dalam penelitian ini adalah:

1. Bagaimana mengembangkan budaya Knowledge Sharing antara pegawai/kader dalam meningkatkan kegiatan penyuluhan keluarga berencana?

2. Bagaimana membagun aplikasi $\mathrm{KM}$ dalam bentuk prototipe untuk meningkatkan pengetahuan para pegawai/kader yang bisa diakses dimanapun?

\section{Tujuan dan Manfaat Penelitian}

Tujuan dari peneletian ini adalah:

1. Untuk meningkatkan produktivitas para pegawai/kader pada penerapan prototipe knowledge management system.

2. Membuat aplikasi KMS penyuluhan keluarga berencana dengan memanfaatkan smartphone android, dan memberikan kemudahan dalam penggunaannya.

Manfaat yang diperoleh dari hasil penelitian ini adalah:

a. Manfaat Praktis

1. Memudahkan pegawai/kader penyuluhan dalam mengakses knowledge management system penyuluhan KB dimana saja dengan menggunakan smartphone android.

2. Lebih mudah mendapatkan pengetahuan praktis tentang keluarga berencana dan berbagi pengetahuan antara pegawai/kader

b. Manfaat Teoritis 
1. Memanfaatkan perkembangan teknologi mobile yang sedang berkembang saat ini dengan optimal.

2. Agar pengetahuan tidak hilang.

\section{LANDASAN TEORI DAN KERANGKA PEMIKIRAN}

\section{Konsep Knowledge Management System}

Ilmu pengetahuan yang maju dengan pesat di dukung dengan perkembangan teknologi yang terus berkembang sehingga hadirnya inovasiinovasi yang baru. Menurut Debowski (2006), knowledge adalah proses menerjemahkan informasi dan pengalaman masa lalu menjadi hubungan bermakna yang dapat dimengerti dan diterapkan oleh setiap individu. Menurut Davidson dan Voss (2003), mereka mengatakan bahwa mengelola knowledge sebenarnya merupakan cara bagaimana organisasi mengelola karyawan mereka, identifikasi pengetahuan yang dimiliki karyawan, menyimpan dan membagi di tim, meningkatkan dan terjadi sebuah inovasi. Jadi menurut mereka knowledge management adalah bagaimana orang-orang dari berbagai tempat yang berbeda mulai saling bicara, yang sekarang populer dengan label learning organization.

$$
\text { Untuk }
$$
membangun

Organizational

Knowledge Management Systems (OKMS) diperlukan empat fungsi yaitu : using knowledge, finding knowledge, creating knowledge dan packaging knowledge yang akan membangun suatu knowledge baru untuk menjawab pertanyaan mengenai know-how, know-what, dan know-why, serta menumbuhkan kreativitas yang ditumbuhkan oleh dirinya sendiri (self-motivated creativity), tacit pribadi (personal tacit), tacit yang membudaya (culture tacit), tacit organisasi (organizational tacit) dan aset peraturan (regulatory assets).

Menurut David J. Skyrme dalam Setiarso (2009) pada the 3Cs of knowledge sharing, salah satu tantangan knowledge management adalah menjadikan manusia berbagi knowledge mereka. Untuk menghadapi tantangan tersebut dia menyarankan tiga $\mathrm{C}$, yaitu Culture, Co-opetition (menyatukan kerjasama dengan persaingan), dan Commitment.

Menurut Hansen dkk dalam Setiarso (2009) mengemukakan bahwa pada dasarnya, strategi organisasi dalam mengelola knowledge terbagi atas dua ekstirm yaitu: strategi kodifikasi (codification strategy) dan strategi personalisasi (personalization strategy). Apabila knowledge diterjemahkan dalam bentuk eksplisit secara berhati-hati (codified) dan disimpan dalam basis data sehingga pengguna yang membutuhkan dapat mengakses knowledge tersebut, cara mengelola seperti itu dikatakan menganut strategi kodifikasi. Namun knowledge tidak hanya eksplisit saja, melainkan juga knowledge yang terpikirkan (tacit). Tacit knowledge sangat sulit diterjemahkan dalam bentuk eksplisit. Oleh sebab itu, knowledge juga bisa dialihkan dari satu pihak ke pihak lain melalui hubungan personal yang intensif. Jadi, disini fungsi utama adalah jaringan komputer baik internet atau intranet. Bukan saja untuk menyimpan atau mendokumentasikan knowledge, melainkan juga untuk memfasilitasi lalu lintas komunikasi antar individu dalam suatu organisasi merupakan strategi personalisasi.

Knowledge organisasi selalu berkembang dari waktu ke waktu, maka Knowledge Management berupa siklus hidup yang ada dalam organisasi.

Daur Knowledge Management menurut Nonaka, Ikujiro dan Takeuchi (1995) mengemukakan suatu model yang menunjukkan suatu daur dalam Knowledge Management. Daur ini terdiri atas empat tahapan dan dikenal dengan nama SECI seperti terlihat pada gambar berikut ini:



Sumber: Nonaka (1995)

Gambar 2.1. Model SECI Nonaka

Arsitektur Knowledge Management System, Amrit Tiwana membuat suatu arsitektur untuk Knowledge Management System yang terdiri atas tujuh lapisan. Dimana setiap lapisan berisi berbagai komponen yang digunakan Knowledge Management System. Lapisan-lapisan dalam arsitektur Knowledge Management System seperti terlihat pada gambar sebagai berikut: 


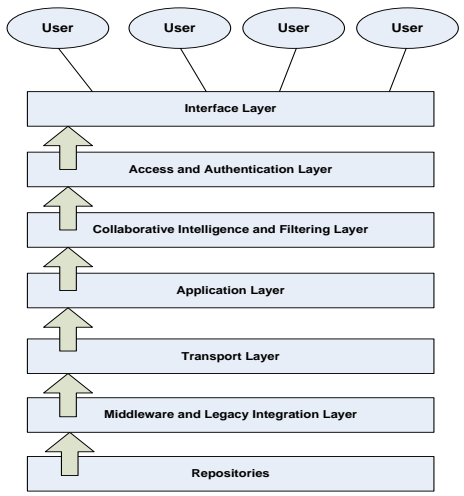

Sumber: Tiwana (2000)

Gambar 2.2. Arsitektur Knowledge Management System Amrit Tiwana

\section{Proses Knowledge Management dalam Organisasi}

Penerapan Knowledge Management pada suatu organisasi merupakan proses yang panjang dan lama, yang mencakup perubahan perilaku semua pegawai. Membangun organisasi berbasis pengetahuan, termasuk kesiapan dan kualitas sumber daya manusia (SDM) sebagai kunci dengan harus membawa penyadaran dalam mengantisipasi kesiapan dalam membangun organisasi yang berbasis pengetahuan.

Kita tengah bergerak dari suatu masyarakat industrial (industrial soociety) ke masyarakat knowledge (knowledge society). Dimana sumber kekayaan bergeser dari modal ke knowledge dan jenis organisasi (organizational type) dari hierarki yang tajam (step hierarchy) menuju ke jejaringan manusia (human networking).

Tiga Hal yang mempengaruhi berhasil tidaknya knowledge management yaitu:

1. Penerapan tidak hanya menghasilkan knowledge baru, tetapi juga mendaur ulang knowledge yang sudah ada,

2. Teknologi informasi belum sepenuhnya bisa menggantikan fumgsi-fungsi jaringan sosial antar anggota organisasi

3. Sebagian besar organisasi tidak tahu apa yang sesungguhnya mereka ketahui, banyak knowledge penting yang harus ditemukan lewat upaya-upaya khusus, padahal knowledge itu sudah dimiliki sebuah organisasi sejak lama.

\section{Android Operating System}

Android adalah sebuah sistem operasi untuk perangkat mobile berbasis linux yang mencakup sistem operasi, middleware dan aplikasi. Android menyediakan platform terbuka bagi para pengembang untuk menciptakan aplikasi sendiri sesuai dengan kebutuhan. Android dikeluarkan oleh Google Inc pada bulan November 2007. Pemrograman perangkat ini menggunakan bahasa pemrograman Extensible Markup Language (XML) dan Java.

1. Fitur-fitur Android

Android memiliki beberapa fitur yang menarik bagi yang ingin mengembangkan aplikasi, diantaranya sebagai berikut :

a. Framework aplikasi yang mendukung penggantian komponen dan reusable

b. Mesin Virtual Dalvik dioptimalkan untuk perangkat mobile

c. Integrated browser berdasarkan engine open source WebKit

d. Grafis yang dioptimalkan dan didukung oleh libraries grafis $2 \mathrm{D}$, grafis $3 \mathrm{D}$ berdasarkan spesifikasi openg1 ES 1,0 (Opsional akselerasi hardware)

e. SQLite untuk penyimpanan data

f. Media Support yang mendukung audio, video, dan gambar (MPEG4, H.264, MP3, AAC, AMR, JPG, PNG, GIF), GSM Telephony (tergantung Hardware)

g. Bluetooth, EDGE, 3G, dan Wifi

h. Kamera, GPS, kompas, dan accelerometer

i. Lingkungan Development yang lengkap dan kaya termasuk perangkat emulator, tools untuk debugging, profil dan kinerja memori, dan plugin untuk IDE Eclipse.

2. Arsitektur Android

Secara garis besar Arsitektur Android dapat dijelaskan dan digambarkan sebagai berikut:

a. Applications dan Widgets

Applications dan Widgets adalah layer di mana dapat berhubungan dengan aplikasi saja.

b. Applications Frameworks

Android adalah "Open Development Platform" yaitu Android menawarkan kepada pengembang atau memberi kemampuan kepada pengembang untuk membangun aplikasi yang bagus dan inovatif.

c. Libraries

Libraries adalah layer di mana fitur-fitur Android berada, biasanya para pembuat aplikasi mengakses libraries untuk menjalankan aplikasinya.

d. Android Run Time

Layer yang membuat aplikasi Android dapat dijalankan di mana dalam prosesnya 
menggunakan Implementasi Linux. Di dalam Android Run Time dibagi menjadi dua bagian yaitu :

1. Core Libraries

2. Dalvik Virtual Machine

e. Linux Kernel

Linux kernel adalah layer di mana inti dari operating sistem dari Android berada.

\begin{tabular}{|c|c|c|c|c|}
\hline \multicolumn{5}{|c|}{ Applications and Widgets } \\
\hline Home & Contacts & Browser & Widgets & Your App Here \\
\hline \multicolumn{5}{|c|}{ Application Framework } \\
\hline $\begin{array}{l}\text { Activity } \\
\text { Manager }\end{array}$ & $\begin{array}{l}\text { Window } \\
\text { Manager }\end{array}$ & $\begin{array}{l}\text { Content } \\
\text { Providers }\end{array}$ & View System & $\begin{array}{l}\text { Notification } \\
\text { Manager }\end{array}$ \\
\hline $\begin{array}{l}\text { Package } \\
\text { Manager }\end{array}$ & $\begin{array}{l}\text { Telephony } \\
\text { Manager }\end{array}$ & Resource & $\begin{array}{l}\text { Location } \\
\text { Manager }\end{array}$ & $\begin{array}{l}\text { Sensor } \\
\text { Manager }\end{array}$ \\
\hline Libraries & & & \multirow{3}{*}{\multicolumn{2}{|c|}{$\begin{array}{l}\text { Android Runtime } \\
\qquad \text { Core Libraries }\end{array}$}} \\
\hline $\begin{array}{l}\text { Surface } \\
\text { Manager }\end{array}$ & $\begin{array}{c}\text { Media } \\
\text { Framework }\end{array}$ & SQLite & & \\
\hline OpenGL | ES & FreeType & Webkit & & \\
\hline SGL & SSL & libc & & \\
\hline \multicolumn{5}{|l|}{ Linux Kernel } \\
\hline Display Driver & $\begin{array}{l}\text { Bluetooth } \\
\text { Driver }\end{array}$ & Camera Driver & $\begin{array}{c}\begin{array}{c}\text { Flash Memory } \\
\text { Driver }\end{array} \\
\end{array}$ & $\begin{array}{l}\text { Binder (IPC) } \\
\text { Driver }\end{array}$ \\
\hline Keypad Driver & USB Driver & WiFi Driver & Audio Drivers & $\begin{array}{c}\text { Power } \\
\text { Management }\end{array}$ \\
\hline
\end{tabular}

Sumber : Nazruddin, 2012

Gambar 2.3 Arsitektur Android

\section{Fundamental Aplikasi}

Aplikasi Android ditulis dalam bahasa pemrograman java. Kode java dikompilasi bersama dengan data file resource yang dibutuhkan oleh aplikasi, di mana prosesnya dipackage oleh tools yang dinamakan "apt tools" ke dalam paket Android sehingga menghasilkan file dengan ekstensi apk. File apk itulah yang disebut dengan aplikasi dan nantinya dapat di install di perangkat mobile.

Ada empat jenis komponen pada aplikasi Android yaitu :
a. Activities
b. Service
c. Broadcast Receiver
d. Content Provider

\section{Model Prototipe}

Model prototipe (prototyping model) dimulai dari mengumpulkan kebutuhan pelanggan terhadap perangkat lunak yang akan dibuat. Lalu dibuatlah program prototipe agar pelanggan lebih terbayang dengan apa yang sebenarnya diinginkan. Program prototipe biasanya merupakan program yang belum jadi. Program ini biasanya menyediakan tampilan dengan simulasi alur perangkat lunak sehingga tampak seperti perangkat lunak yang sudah jadi. Program prototipe dievaluasi oleh pelanggan atau user sampai ditemukan spesifikasi yang sesuai dengan keinginan pelanggan atau user. Berikut adalah gambar atau model prototipe :

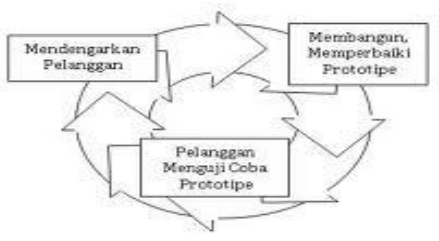

$\mathrm{Su}$

$\mathrm{mb}$

er :

Ros

a,

201

1

Permasalahan dapat terjadi pada model prototipe, hal ini dapat diatasi dengan melakukan perjanjian antara pengembang perangkat lunak dengan pelanggan atau user agar model prototipe hanya digunakan untuk mendefinisikan spesifikasi kebutuhan perangkat lunak, tapi tidak untuk seluruh proses pengembangan seluruh sistem perangkat lunak.

Model prototipe cocok digunakan untuk menjabarkan kebutuhan pelanggan secara lebih detail karena pelanggan sering kali kesulitan menyampaikan kebutuhannya secara detail tanpa melihat gambaran yang jelas. Untuk mengantisipasi agar proyek dapat berjalan sesuai dengan target waktu dan biaya di awal, maka sebaiknya spesifikasi kebutuhan sistem harus sudah disepakati oleh pengembang dengan pelanggan secara tertulis. Dokumen tersebut akan menjadi dasar agar spesifikasi kebutuhan sistem masih dalam ruang lingkup proyek.

\section{Kerangka Pemikiran}

Pada penulisan penelitian ini terlebih dahulu menjabarkan kerangka pemikiran sebagai berikut: 


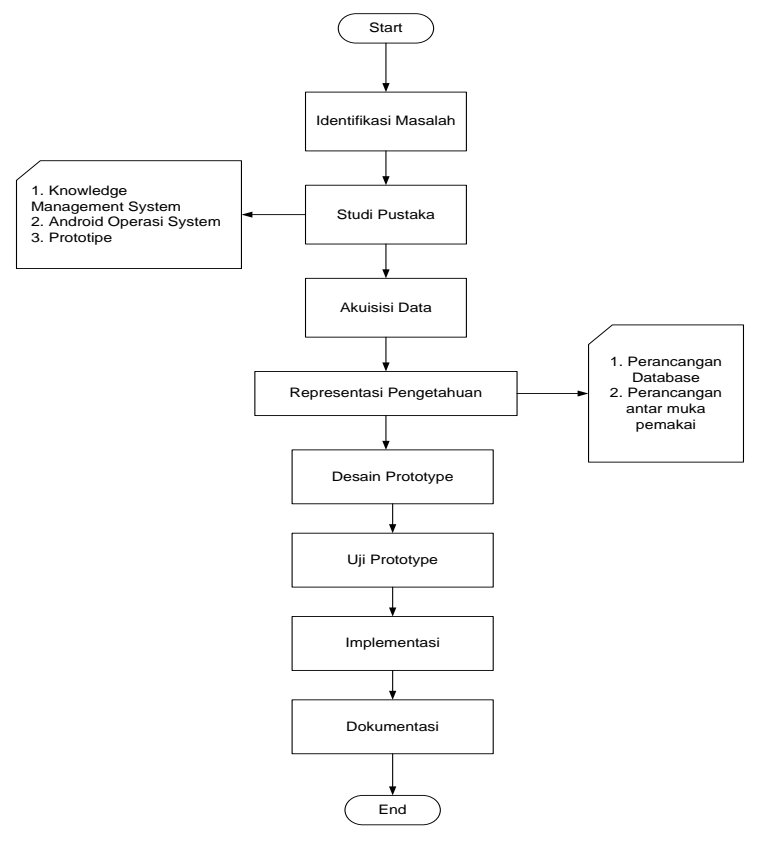

Gambar 2.5 Kerangka Pemikiran

\section{METODOLOGI PENELITIAN}

\section{Jenis Penelitian}

Penelitian ini menggunakan penelitian deskriptif kuantitatif. Data yang diperoleh dari sample populasi penelitian diambil sesuai dengan metode statistik yang digunakan kemudian diinterprestasikan, dan didukung dengan metode The Most Admire Knowledge Enterprise (MAKE) Langkah-langkah penelitian deskriptif:

a) Mengidentifikasi adanya permasalahan yang signifikan untuk dipecahkan melalui metode deskriptif.

b) Membatasi dan merumuskan permasalahan secara jelas

c) Menentukan tujuan dan manfaat penelitian

d) Melakukan studi pustaka yang berkaitan dengan permasalahan

e) Menentukan kerangka berfikir dan pertanyaan penelitian dan atau hipotesis penelitian.

f) Mendesain metode penelitian yang hendak digunakan termasuk dalam hal ini menentukan populasi, sampel, teknik sampling, menentukan instrument pengumpul data, dan menganalisis data.

g) Mengumpulkan, mengorganisasi, dan menganalisis data dengan menggunakan teknik statistik yang relevan.

h) Membuat laporan penelitian.

\section{Metode Pengumpulan Data}

Metode pengumpulan data dapat dilakukan dengan beberapa cara yaitu observasi (pengamatan), kuesioner, dan studi pustaka. Data dan informasi yang dikumpulkan dalam penelitian ini adalah data primer dan data sekunder. Data primer diperoleh dengan menggunakan metode kuesioner yaitu dengan memberikan daftar pertanyaan kepada responden yang merupakan pegawai/kader Badan Pemberdayaan Perempuan Perlindungan Anak dan Keluarga Berencana (BP3AKB) Kota Bekasi yang dipilih secara tertulis. Sedangkan data sekunder didapatkan dati studi literatur, tulisan ilmiah tentang knowledge management dan knowledge sharing yang ada dilingkungan akademik dan internet.

\section{Teknik Pengumpulan Sampel}

Teknik pengumpulan sample yang digunakan pada penelitian ini adalah random sampling (probability sampling). Menurut Sugiyono (2009) random sampling adalah teknik yang memberikan peluang yang sama bagi setiap unsur atau anggota populasi untuk dipilih menjadi anggota sample. Dan Ukuran sample yang diambil menurut Gay dan Diehl (1996) untuk penelitian deskriptif minimal $10 \%$ dari populasi. Hal ini dilakukan karena jumlah populasi yang merupakan pegawai/kader BP3AKB Kota Bekasi tersebar diwilayah-wilayah yang terpisah. Kota Bekasi terdiri dari 12 Kecamatan dan 56 Kelurahan. Sehingga sample yang diambil sebagai studi kasus adalah para pegawai/kader setiap kecamatan sebagai sample dengan jumlah sample adalah 14 Responden.

\section{Instrumentasi}

Penelitian ini menggunakan metode penelitian kuantitatif, yaitu penelitian yang dilakukan dengan cara memberi seperangkat pertanyaan kepada responden untuk dijawab. Kuesioner yang berbentuk Checklist dengan Skala Likert diberikan kepada orang-orang yang akan menggunakan aplikasi KMS berbasis android tersebut untuk diisi. Skala likert didesain untuk menilai sejauh mana subyek setuju atau tidak setuju dengan pernyataan yang diajukan. Didalam penelitian menggunakan skala likert ini umumnya menggunakan lima point dimulai dari 5 (Sangat Setuju/SS), 4 (Setuju/S), 3 (Netral/N), 2 (Tidak setuju/ TS), dan 1 (Tidak Sangat Setuju/TST).

Dalam penelitian ini peneliti menyebarkan kuesioner sebanyak dua kali, kuesioner yang pertama digunakan untuk melakukakn analisa 
kebutuhan terhadap KMS yang akan dirancang (Pra Desain). Kuesioner berisi 10 pertanyaan dan disebarkan kepada 14 pegawai/kader yang merupakan responden. Kuesioner yang kedua untuk mengukur kinerja aplikasi KMS berbasis android bagi pegawai/kader pada bidang KB di BP3AKB Kota Bekasi yang terdiri dari 15 pertanyaan. Dimana tiap butir disiapkan 5 interval jawaban. awabannya terendah diberi skor 1 dan jawaban tertinggi diberi skor 5 .

\section{PEMBAHASAN}

\section{Profil Responden}

Dalam penelitian ini menyebarkan 10 lembar kuesioner kepada para guru dan siswa di lingkungan Primagama, yang meliputi lima kuesioner untuk para guru, dan lima kuesioner untuk para siswa. Hal ini dilakukan untuk mengetahui apakah Penerapan Knowledge Management berbasis mobile Android dapat bermanfaat dan menunjang proses Knowledge Managementnya. Dan melihat apakah dari segi lembaga sudah siap dalam penerapan Knowledge Management berbasis mobile Andr Dalam penelitian ini, penulis menyebarkan kuesioner kepada 14 responden yaitu pegawai/kader di bidang KB pada Badan Pemberdayaan Perempuan Perempuan Perlindungan Anak dan Keluarga Berencana (BP3AKB) yang tersebar disetiap kecamatan Kota Bekasi. Kuesioner yang disebarkan untuk mengetahui apakah prototipe knowledge management system yang berbasis Android dapat bermanfaat dan menunjang proses knowledge management dalam proses penyuluhan di BP3AKB dan juga untuk mengukur seberapa penting kinerja aplikasi knowledge management system tersebut bagi pegawai dan kader-kader BP3AKB Kota Bekasi.

Kuesioner ini terdiri dari empat bagian, yaitu bagian pertama tentang profil pegawai dan kader, bagian kedua adalah tanggapan para pegawai dan kader tentang penerapaan prototipe knowledge management system yang berbasis Android, bagian ketiga adalah profil Kepala Bidang, dan bagian keempat tanggapan Kepala Bidang mengenai penerapan prototipe KMS guna meningkatkan efektifitas dan prestasi para pegawai serta kader dalam proses penyuluhan.

Untuk mendapatkan gambaran mengenai pegawai dan kader yang menjadi responden dalam penelitian ini, berikut akan diuraikan pengelompokkan responden berdasarkan usia pegawai, lokasi kerja, kepemilikan Android, dan cara mendapatkan pegawai dan pengetahuan tentang penyuluhan di BP3AKB. Adapun data yang penulis peroleh mengenai profil responden sebagai berikut:

Tabel 4.1 Data Responden Pegawai/Kader

\begin{tabular}{|c|c|c|}
\hline Klasifikasi Responden & Jumlah & Persentase \\
\hline $\begin{array}{l}\text { 1. Usia: } \\
<25 \text { tahun } \\
25-40 \text { tahun } \\
41-50 \text { tahun } \\
>51 \text { tahun }\end{array}$ & $\begin{array}{l}3 \\
5 \\
4 \\
2\end{array}$ & $\begin{array}{l}21 \% \\
36 \% \\
29 \% \\
24 \%\end{array}$ \\
\hline Total & 14 & $100 \%$ \\
\hline $\begin{array}{l}\text { 2. Lolasi Kerja: } \\
\text { Kecamstan Bantar Gebang } \\
\text { Kecamatan Belsai Barat } \\
\text { Kecamatan Belkasi Selatan } \\
\text { Kecamatan Belkasi Timur } \\
\text { Kecamatan Belkasi Utara } \\
\text { Kecamatan Jatiasih } \\
\text { Kecamatan Jatiampuma } \\
\text { Kecamatan Medan Satria } \\
\text { Kecamatan Mustika Jaya } \\
\text { Kecamatan Pondol: Gede } \\
\text { Kecamatan Pondok Metali } \\
\text { Kecamatan Rawalumbu }\end{array}$ & $\begin{array}{l}1 \\
1 \\
2 \\
1 \\
1 \\
1 \\
1 \\
1 \\
1 \\
2 \\
1 \\
1\end{array}$ & $\begin{array}{l}7 \% \\
7 \% \\
14 \% \\
7 \% \\
7 \% \\
7 \% \\
7 \% \\
7 \% \\
7 \% \\
14 \% \\
7 \% \\
7 \%\end{array}$ \\
\hline Total & 14 & $100 \%$ \\
\hline $\begin{array}{l}\text { 3. Kepenilikan Android } \\
\text { Memiliki } \\
\text { Tidak memiliki }\end{array}$ & $\begin{array}{c}11 \\
3\end{array}$ & $\begin{array}{l}79 \% \\
21 \%\end{array}$ \\
\hline Total & 14 & $100 \%$ \\
\hline $\begin{array}{l}\text { 4. Mendapatkan pengetahuan } \\
\text { Rekan Kerja } \\
\text { Intemet } \\
\text { Buku } \\
\text { Pengalaman }\end{array}$ & $\begin{array}{l}2 \\
4 \\
5 \\
3\end{array}$ & $\begin{array}{l}14 \% \\
29 \% \\
36 \% \\
21 \%\end{array}$ \\
\hline Total & 14 & $100 \%$ \\
\hline
\end{tabular}

Sumber : data kuesioner yang telah diolah 
Tabel 4.2.Tabel Data Responden Kepala Bidang

\begin{tabular}{|c|c|c|}
\hline Klasifikasi Responden & Jumlah & Persentase \\
\hline $\begin{array}{l}\text { Usia: } \\
25 \text { tahun } \\
25-40 \text { tahun } \\
41-50 \text { tahun } \\
>51 \text { tahun }\end{array}$ & $\begin{array}{l}0 \\
0 \\
3 \\
1\end{array}$ & $\begin{array}{c}0 \% \\
0 \% \\
75 \% \\
25 \%\end{array}$ \\
\hline Total & $\frac{4}{4}$ & $100 \%$ \\
\hline 2. Lokasi Kerja: & & \\
\hline Bantar Gebang & 1 & $25 \%$ \\
\hline Bekasi Barat & 0 & $0 \%$ \\
\hline Bekasi Selatan & 1 & $25 \%$ \\
\hline Bekasi Timur & 1 & $25 \%$ \\
\hline Bekassi Utara & 0 & $0 \%$ \\
\hline Jatiasih & 0 & $0 \%$ \\
\hline Jatisampuma & 0 & $0 \%$ \\
\hline Medan Satria & 0 & $0 \%$ \\
\hline Mustika Jaya & 0 & \\
\hline Pondok Gede & 0 & $0 \%$ \\
\hline Pondok Metali & 1 & $0 \%$ \\
\hline Rawalumbu & 0 & $25 \%$ \\
\hline & & $0 \%$ \\
\hline Total & 4 & $100 \%$ \\
\hline 3. Kepemilikan Android & & \\
\hline Nemiliki & 3 & $75 \%$ \\
\hline Tidak memiliki & 1 & $25 \%$ \\
\hline Total & 4 & $100 \%$ \\
\hline 4. Nendapatkan pengetahuan & & \\
\hline Rekan Kerja & 1 & $25 \%$ \\
\hline Intemet & 0 & $0 \%$ \\
\hline Buku & 2 & $50 \%$ \\
\hline Pengalaman & 1 & $25 \%$ \\
\hline Total & 4 & $100 \%$ \\
\hline
\end{tabular}

Sumber : data kuesioner yang telah diolah

Berikut ini hasil dari penyebaran kuesioner kepada responden para pegawai dan kader di Badan Pemberdayaan Perempuan Perlindungan Anak dan Keluarga Berencana (BP3AKB) yang tersebar disetiap kecamatan Kota Bekasi mengenai tanggapan penerapan prototipe Knowledge Management System dalam penyuluhan yang berbasis Android. Setiap jawaban dari responden diberi nilai berdasarkan skala Likert. Berikut ini adalah kriteria penilaiannya:

Tabel 4.3. Kriteria penilaian skala likert

\begin{tabular}{|c|c|c|}
\hline SS & Sangat setuju & 5 \\
\hline S & Setuju & 4 \\
\hline N & Netral & 3 \\
\hline TS & Tidak setuju & 2 \\
\hline STS & Sangat tidak setuju & 1 \\
\hline
\end{tabular}

Selanjutnya jawaban dari responden tersebut diberi nilai berdasarkan kriteria penilaian dari skala likert, setelah dikalikan lalu dijumlahkan dan dicari rata-rata dari setiap jawaban responden tersebut, maka dibuatlah interval. Dalam penelitian ini penulis menentukan banyak kelas interval sebesar 5 .

Penulis menggunakan rumus menurut Sudjana (2002), rumus yang menjadi dasar tersebut adalah sebagai berikut :

$$
P=\frac{\text { rentang }}{\text { Banyak kelas }}
$$

$\mathrm{P} \quad=$ Panjang kelas interval

Rentang $\quad=$ Data terbesar-Data terkecil

Banyak Kelas $=5$

Jadi, panjang kelas interval adalah

$$
\begin{array}{ll}
P=\frac{5-1}{5} & \text { Maka interval dari kriteria penilaian } \\
P=0,8 & \text { rata-rata adalah sebagai berikut : }
\end{array}
$$

Sangat Buruk (SBR) / Sangat Rendah $(\mathrm{SR})=$ $1,00-1,79$

Buruk (BR) / Rendah $(R)=1,80-2,59$

Cukup Baik (CB) / Cukup Tinggi $(\mathrm{CT})=2,60-$ 3,39

Baik (B) / Tinggi $(\mathrm{T})=3,40-4,19$

Sangat Baik (SB) / Sangat Tinggi $(\mathrm{ST})=4,20-$ 5,00

Tabel 4.4 Analisa Kebutuhan Knowledge Management System Berbasis Android (Pra Desain) 


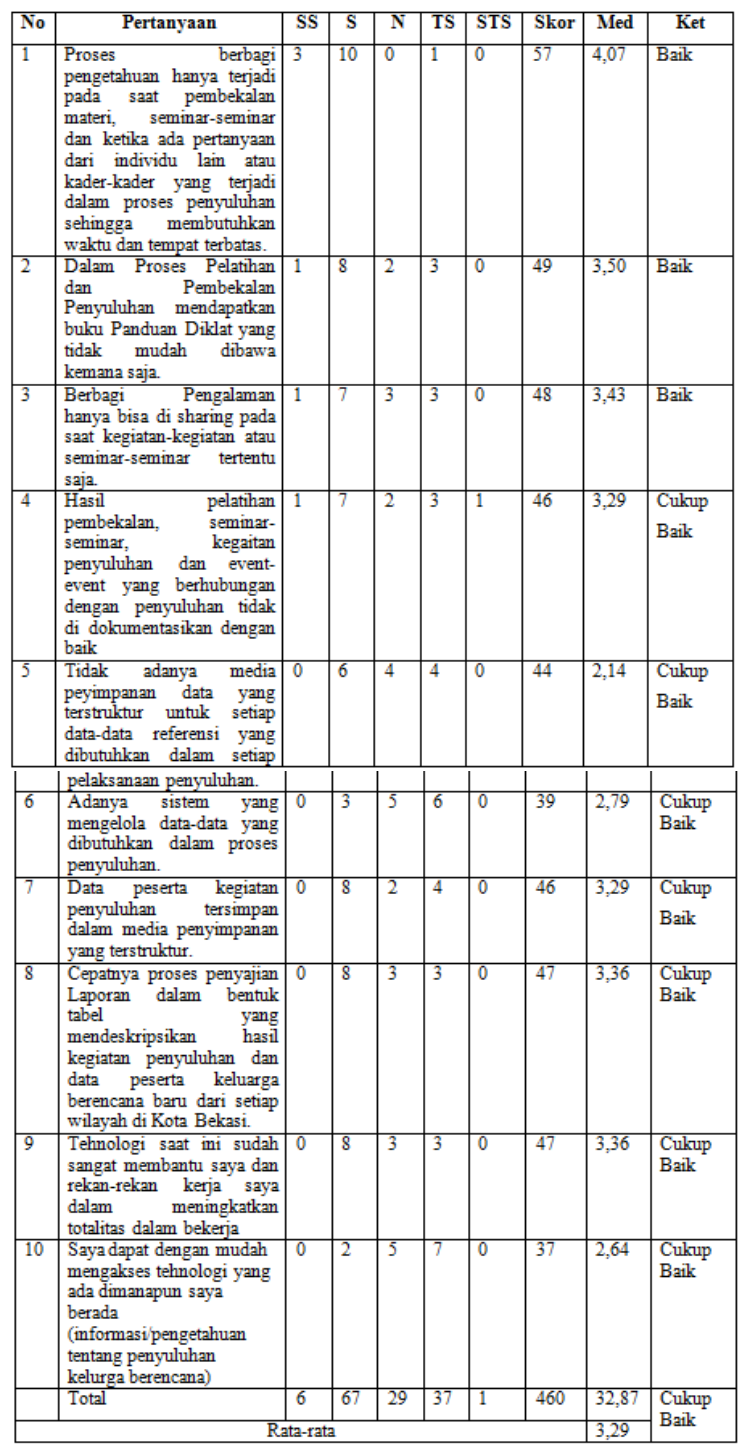

Sumber : data kuesioner yang telah diolah

Berdasarkan dari data yang telah diolah didapatkan kesimpulan bahwa kebutuhan KMS di BP3AKB dibutuhkan. Dimasa sekarang, teknologi merupakan faktor penting untuk meningkatkan totalitas bekerja. Artinya pembuatan KMS yang berbasis Android ini dapat meningkatkan efektifitas dan totalitas bekerja. Nilai rata-rata keseluruhan pernyataan sebesar 3,29 yang berada pada interval 2,60 - 3,39.

Tabel 4.5. Tanggapan Pegawai/Kader tentang Penerapan Knowledge Management System berbasis Android Pada BP3AKB

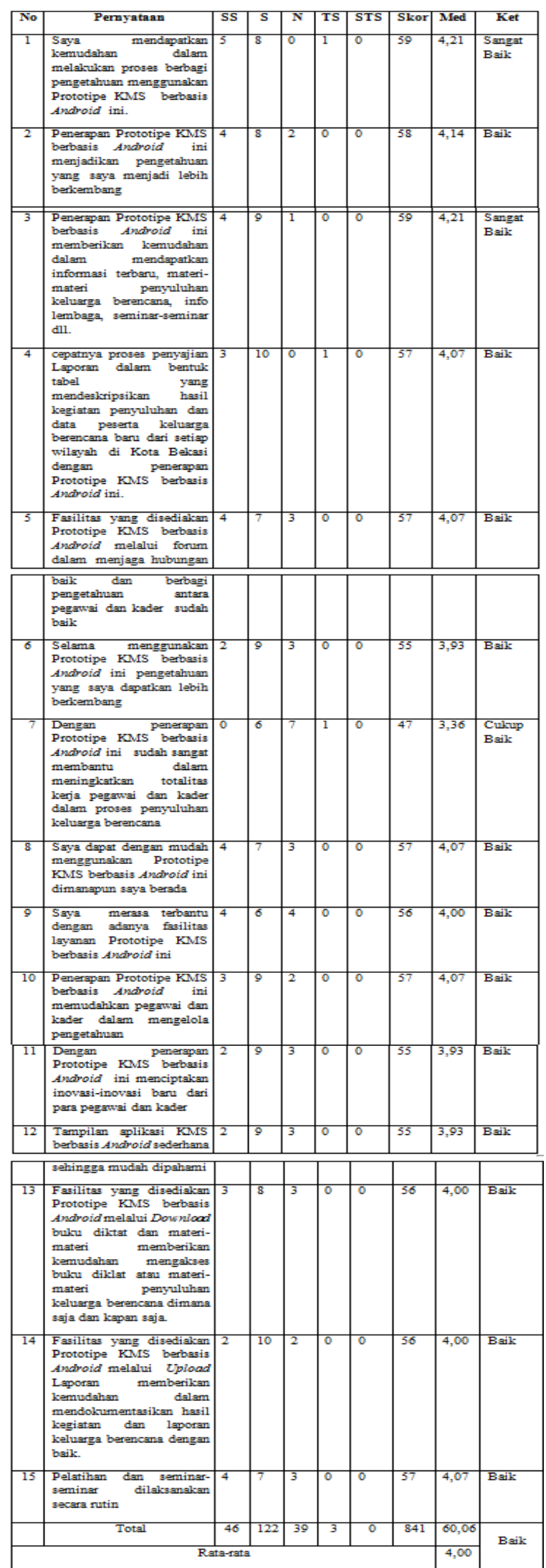


Sumber : data kuesioner yang telah diolah

Dari keseluruhan data yang sudah diolah, dapat disimpulkan bahwa tanggapan terhadap penerapan prototipe KMS ini dikatakan baik, artinya penerapan prototipe KMS yang berbasis Android ini dapat diterima dan dapat digunakan dengan baik oleh para pegawai dan kader di BP3AKB Kota Bekasi nilai rata-rata dari keseluruhan sebesar 4,00 yang berada pada interval $3,40-4,19$. Penerapan prototipe KMS yang berbasis Android sangat dibutuhkan didukung dengan perkembangan teknologi yang semakin maju menjadikan informasi dan pengetahuan yang ada dapat terus terjaga dan diturunkan ke pegawai dan kader dimasa mendatang.

Sedangkan hasil pengolahan data kuesioner yang telah disebarkan kepada bidang, dapat disimpulkan bahwa penerapan prototipe knowledge management system berbasis Android dapat diterima dengan baik. Nilai rata-rata dari keseluruhan pernyataan sebesar 3,83 yang berada pada interval $3.40-4,19$.

Dengan penerapan prototipe KMS Android ini, telah terciptanya budaya berbagi pengetahuan dan mengolah pengetahuan yang lebih baik. Sebagai contoh, para pegawai dan kader dapat dengan mudah berinteraksi dan menanyakan permasalahan seputar penyuluhan melalui forum, pegawai dapat mengupload laporan PLKB dan melihat laporannya dalam bentuk tabel dan pegawai atau kader juga dapat mendownload buku panduan diklat dan materi-materi yang berhubungan dengan penyuluhan dalam bentuk pdf dapat dilakukan dengan mudah.

\section{Analisis Kebutuhan Sistem}

Tahap analisis sistem merupakan tahap yang sangat penting dan sangat kritis, karena kesalahan di dalam tahap ini akan menyebabkan juga kesalahan di tahap selanjutnya. Pada tahap analisis prototipe Knowledge Management System untuk meningkatkan penyuluhan keluarga berencana berbasis Android ini pendekatan desain dan analisis berorientasi objek atau Object Oriented Analysis and Design (OOAD) dengan menggunakan notasi Unified Modeling Language (UML).

\section{Use Case Diagram Penggunaan Fitur Umum 1. Pegawai/Kader}

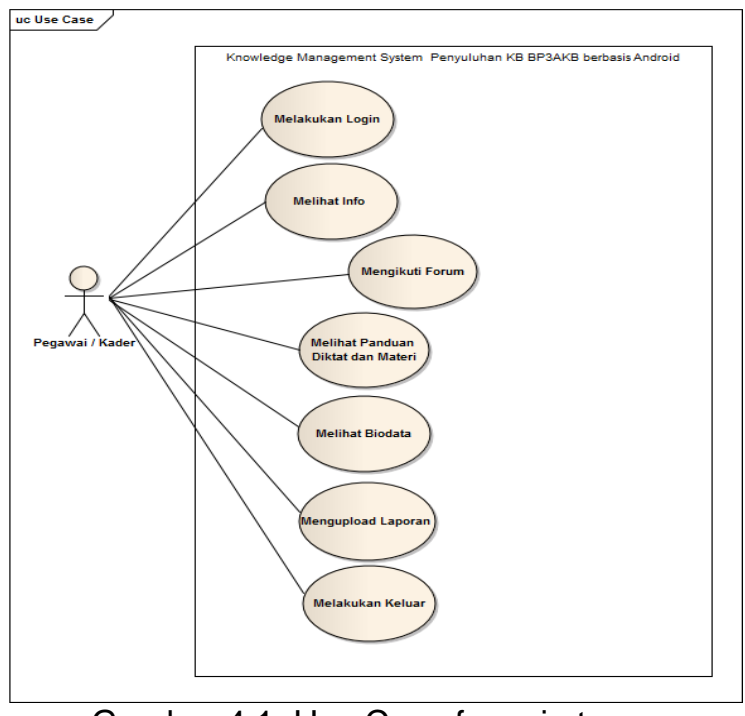

Gambar 4.1 Use Case fungsi utama Pegawai/kader

\section{Admin}

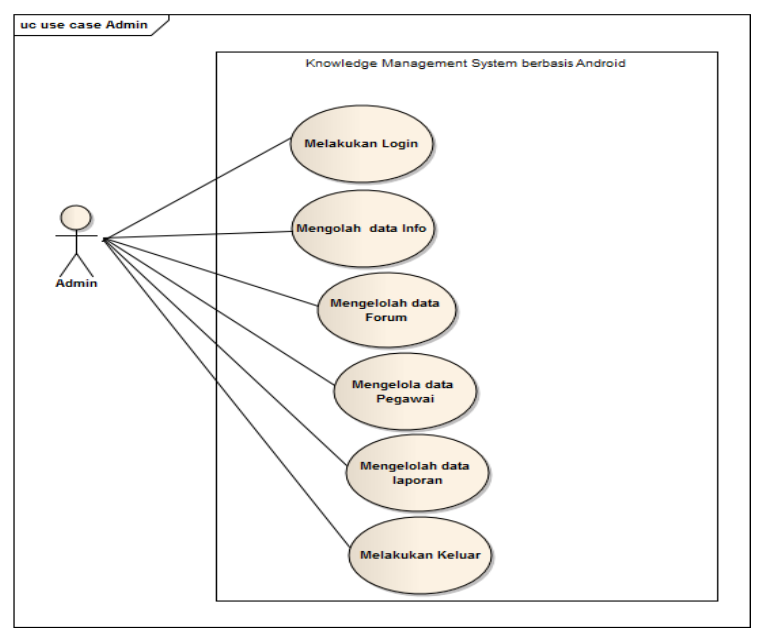

Gambar 4.2 Usecase fungsi Pengelola Sistem (Admin)

\section{Desain Sistem}

Berdasarkan rekomendasi hasil dari analisis sistem, maka analis sistem harus memikirkan bagaimana membentuk dan mengembangkan sistem tersebut. Berikut ini adalah graphical user interface (GUI) yang dirancang untuk prototipe aplikasi KMS berbasis android, yaitu:

a. Tampilan Login 


\section{Login Pengguna}
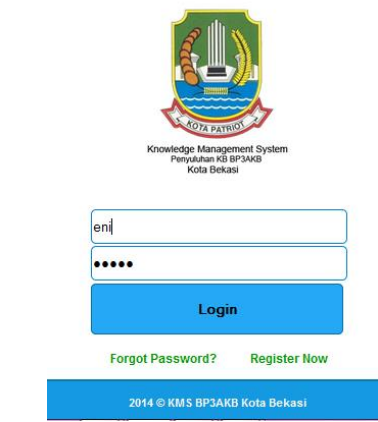

Gambar 4.3 Tampilan Login

b. Tampilan Menu Utama
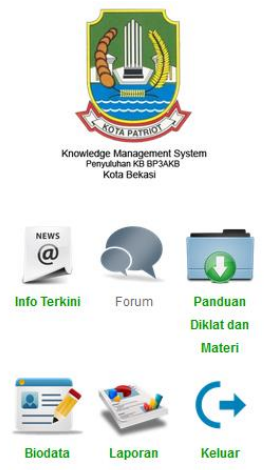

Gambar 4.4 Tampilan Menu Utama

c. Menu Laporan

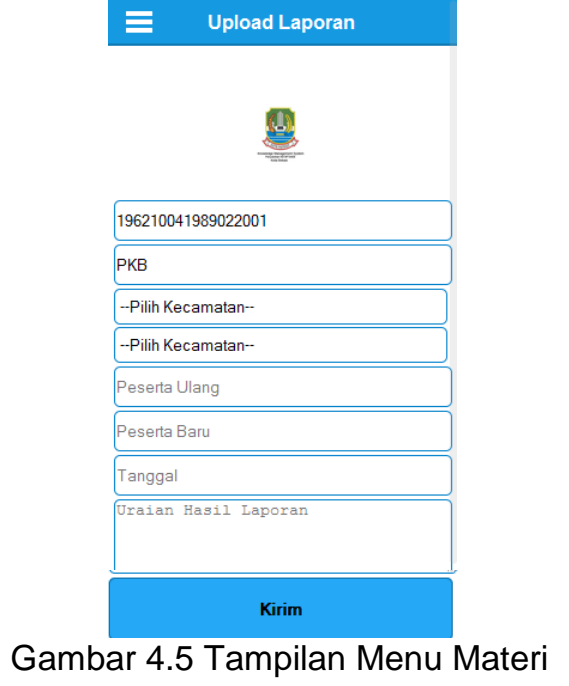

d. Menu Panduan Diktat dan Materi

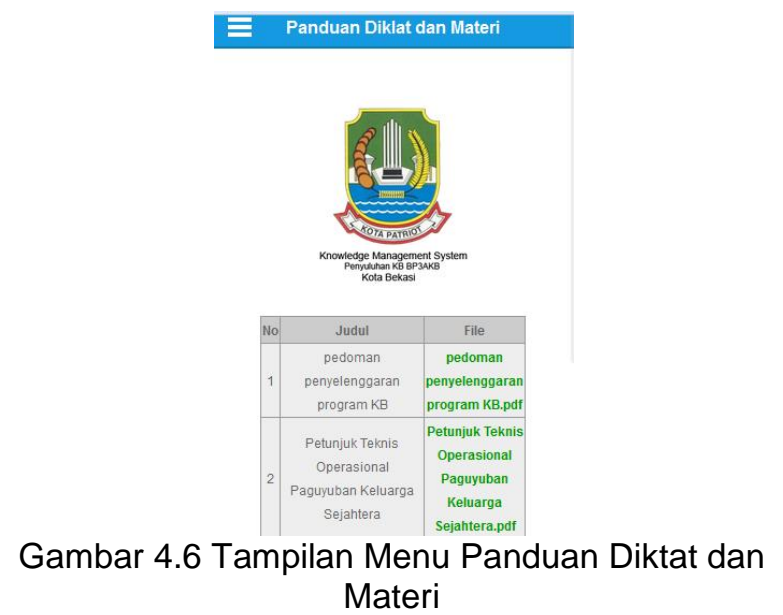

e. Menu Biodata
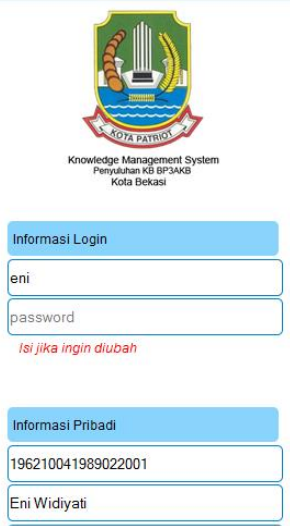

Gambar 4.7 Tampilan Menu Biodata

Hasil Pengujian Prototipe Perangkat Lunak Untuk memastikan bahwa perangkat lunak yang dibuat memiliki standar minimal kualitas, maka salah satu metode untuk pengukuran kualiatas perangkat lunak secara kuantitatif adalah metode SQA (Software Quality Assurance).

Tabel 4.6 Metric Of Software Quality Assurance (SQA) Kuantitatif 


\begin{tabular}{|l|l|l|l|}
\hline No & \multicolumn{1}{|c|}{ Metrik } & \multicolumn{1}{|c|}{ Deskripsi } & Bobot \\
\hline 1 & Auditability & $\begin{array}{l}\text { prototipe KMS ini telah memenuhi standard } \\
\text { kebutuhan sistem }\end{array}$ & 0.125 \\
\hline 2 & Accuracy & $\begin{array}{l}\text { prototipe KMS ini memenuhi keakuratan dalam } \\
\text { penggunaannya. }\end{array}$ & 0.125 \\
\hline 3 & Completeness & $\begin{array}{l}\text { menu pada prototipe KMS ini telah lengkap } \\
\text { semua sesuai dengan kebutuhan sistem }\end{array}$ & 0.125 \\
\hline 4 & Error Tolerance & $\begin{array}{l}\text { Toleransi terhadap kesalahan yang dilakukan } \\
\text { oleh user }\end{array}$ & 0.125 \\
\hline 5 & $\begin{array}{l}\text { Execution } \\
\text { Efficiency }\end{array}$ & $\begin{array}{l}\text { kinerja eksekusi dari prototipe KMS berbasis } \\
\text { smartphone android ini sudah baik }\end{array}$ & 0.125 \\
\hline 6 & Operability & $\begin{array}{l}\text { prototipe KMS berbasis smartphone android ini } \\
\text { mudah untuk dioperasikan }\end{array}$ & 0.125 \\
\hline 7 & Simplicity & $\begin{array}{l}\text { prototipe KMS ini penggunaannya mudah } \\
\text { untuk dipahami }\end{array}$ & 0.125 \\
\hline 8 & Training & prototipe KMS ini mudah untuk dipelajari & 0.125 \\
\hline
\end{tabular}

Berikut adalah pengukuran kualitas perangkat lunak secara Kualitatif dengan menggunakan metode penilaian skala likert, di bawah ini adalah tabel kriteria skala penilaian:

Tabel 4.7. Kriteria Skala Penilaian Kualitas Perangkat Lunak

\begin{tabular}{|c|l|c|c|}
\hline Skala & \multicolumn{1}{|c|}{ Keterangan } & Bobot & $\begin{array}{c}\text { Nilai } \\
\text { Jawaban }\end{array}$ \\
\hline SO & Sangat Optimal & 5 & $81-100$ \\
\hline O & Optimal & 4 & $61-80$ \\
\hline CO & Cukup Optimal & 3 & $41-60$ \\
\hline TO & Tidak Optimal & 2 & $21-40$ \\
\hline STO & $\begin{array}{l}\text { Sangat tidak } \\
\text { Optimal }\end{array}$ & 1 & $0-20$ \\
\hline
\end{tabular}

Sumber: Sugiyono (2012)

Berikut delapan kriteria yang digunakan untuk mengukur kualitas dari perangkat lunak secara kualitatif dengan menggunakan metode penilaian skala likert adalah:

Tabel 4.8. Metric Of Software Quality Assurance (SQA) Kualitatif

\begin{tabular}{|c|c|c|c|c|}
\hline No & Metrik & Skala Pengukuran & Bobot & Standar Penilaian \\
\hline 1 & Auditability & $\begin{array}{l}\text { 1. Sangat Optimal } \\
(81-100) \\
\text { 2. Optimal }(61-80) \\
\text { 3. Cukup Optimal } \\
(41-60) \\
\text { 4. Tidak Optimal } \\
(21-40) \\
\text { 5. Sangat tidak } \\
\text { Optimal }(0-20)\end{array}$ & $\begin{array}{l}4 \\
3 \\
2\end{array}$ & $\begin{array}{l}\text { 1. Sangat optimal, jika aplikasi } \\
\text { mi sangat memenuhi standar } \\
\text { kebutuhan } \\
\text { 2. Optimal, jika aplikasi ini } \\
\text { memenuhi standar kebutuhan } \\
\text { 3. Cukup optimal, jika aplikasi } \\
\text { mi cukup memenuhi standar } \\
\text { kebutuhan. } \\
\text { 4. Tidak optimal, jika aplikasi ini } \\
\text { tidak memenuhi standar } \\
\text { kebutuhan. } \\
\text { 5. Sangat tidak optimal, jika } \\
\text { aplikasi ini sangat tidak } \\
\text { memenuhi standar kebutuhan. }\end{array}$ \\
\hline 2 & Accuracy & $\begin{array}{l}\text { 1. Sangat Optimal ( } 81 \\
-100)\end{array}$ & 5 & $\begin{array}{|lr|}\text { 1. Sangat optimal, jika aplikasi } \\
\text { ini sangat } & \text { memenuhi } \\
\text { keakuratan } & \text { dalam }\end{array}$ \\
\hline
\end{tabular}

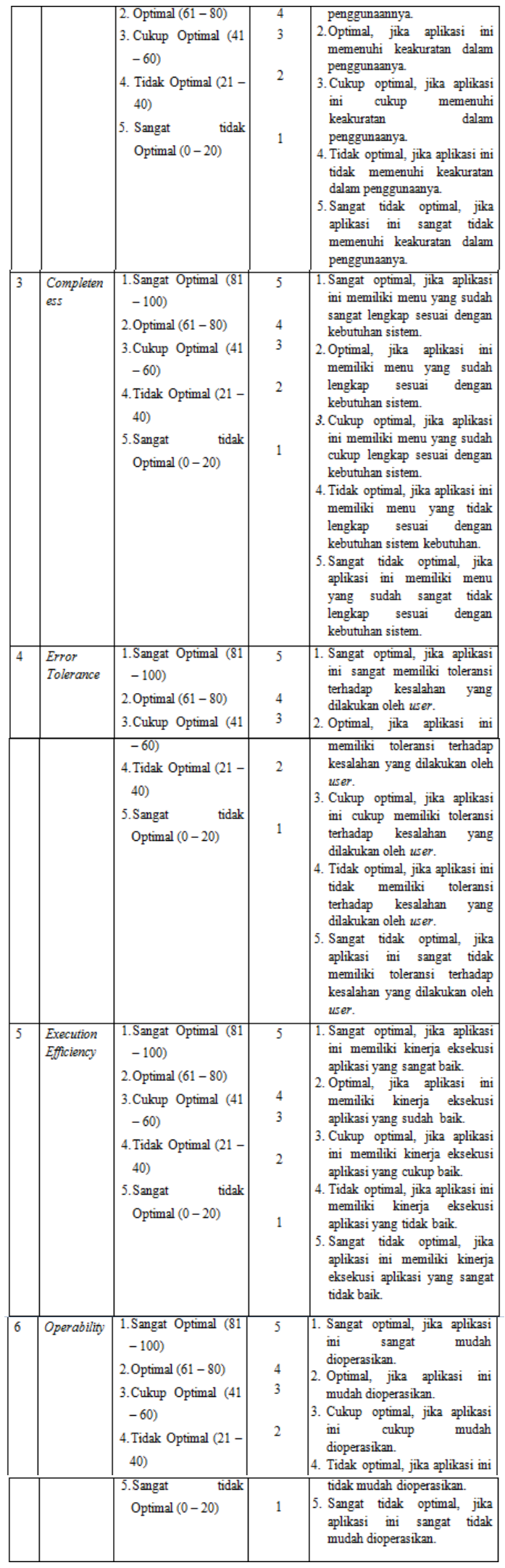




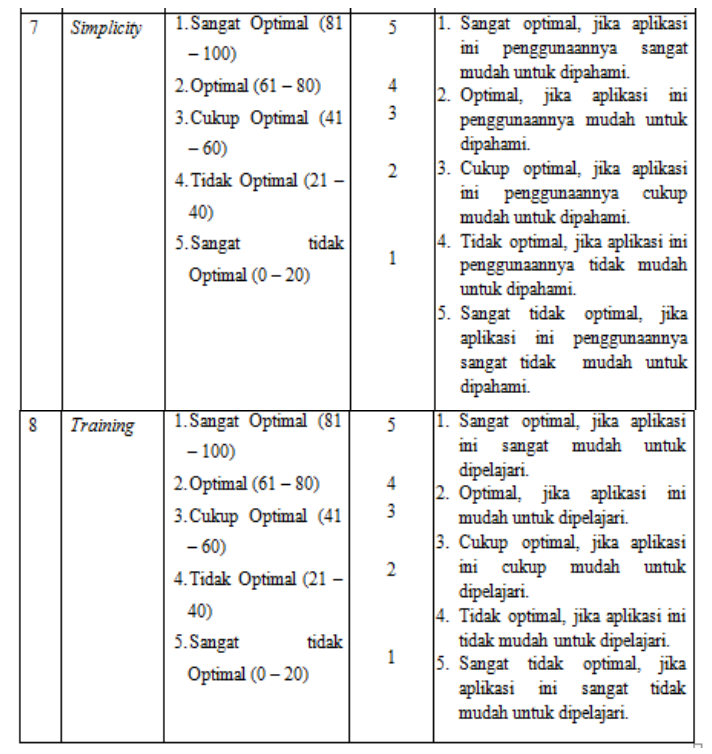

4.9 Hasil Evaluasi SQA

\begin{tabular}{|c|c|c|c|c|c|c|c|c|c|}
\hline \multirow[b]{2}{*}{ User } & \multicolumn{8}{|c|}{ Skor Metrik } & \multirow[b]{2}{*}{ Skor } \\
\hline & 1 & 2 & 3 & 4 & 5 & 6 & 7 & 8 & \\
\hline$\# 1$ & 80 & 77 & 72 & 80 & 75 & 85 & 85 & 75 & 78,6 \\
\hline$\# 2$ & 80 & 75 & 75 & 80 & 78 & 75 & 80 & 78 & 77,6 \\
\hline$\# 3$ & 82 & 80 & 82 & 89 & 86 & 85 & 88 & 80 & 84,0 \\
\hline$\# 4$ & 80 & 90 & 85 & 85 & 75 & 75 & 80 & 80 & 81,3 \\
\hline$\# 5$ & 84 & 78 & 79 & 80 & 85 & 80 & 80 & 73 & 79,9 \\
\hline$\# 6$ & 83 & 87 & 80 & 80 & 80 & 80 & 80 & 70 & 80,0 \\
\hline$\# 7$ & 75 & 80 & 78 & 80 & 80 & 90 & 85 & 80 & 81,0 \\
\hline$\# 8$ & 85 & 80 & 83 & 84 & 90 & 90 & 90 & 87 & 86,1 \\
\hline$\# 9$ & 80 & 78 & 85 & 80 & 80 & 86 & 85 & 76 & 81,3 \\
\hline$\# 10$ & 80 & 75 & 85 & 80 & 80 & 80 & 75 & 78 & 79,1 \\
\hline$\# 11$ & 80 & 80 & 80 & 85 & 80 & 75 & 80 & 70 & 78,8 \\
\hline$=12$ & 70 & 80 & 80 & 80 & 80 & 85 & 85 & 80 & 80,0 \\
\hline$\# 13$ & 70 & 80 & 80 & 80 & 80 & 80 & 80 & 75 & 78,1 \\
\hline$\# 14$ & 75 & 80 & 83 & 80 & 85 & 90 & 80 & 85 & 82,3 \\
\hline \multicolumn{9}{|c|}{ Rata-Rata } & 80,57 \\
\hline
\end{tabular}

Data diatas merupakan hasil angket yang dilakukan pada 14 orang pengamat yang berperan sebagi user.

Skor $\quad=\quad<$ SkorAuditability $>{ }^{*} 0.125+$

$<$ SkorAccuracy $>{ }^{*} 0.125$

$<$ SkorCompleteness>*0.125

$<$ SkorErrorTolerance $>^{*} 0.125$

$<$ SkorExecutionEfficiency $>^{*} 0.125$

$<$ SkorOperability $>^{*} 0.125+<$ SkorSimplicity $>^{*} 0.125$

$+<$ SkorTraining $>^{*} 0.125$

Skor rata-rata yang dihasilkan adalah 80.57, sudah melebihi nilai optimal untuk sebuah perangkat lunak yang memenuhi standar kualitas berdasarkan uji SQA adalah 80.

Tabel 4.10 Hasil Perhitungan Skala Penilaian Masing-Masing Matrik

\begin{tabular}{|l|c|c|c|c|c|c|}
\hline \multirow{2}{*}{ Metriks } & \multicolumn{5}{|c|}{ Skala Penilaian } & $\begin{array}{c}\text { Jumlah } \\
\text { Jawaban }\end{array}$ \\
\cline { 2 - 6 } & $\begin{array}{c}\text { Sangat } \\
\text { Optimal }\end{array}$ & Optimal & $\begin{array}{l}\text { Cukup } \\
\text { Optimal }\end{array}$ & $\begin{array}{c}\text { Tidak } \\
\text { Optimal }\end{array}$ & $\begin{array}{c}\text { Sangat } \\
\text { Tidak } \\
\text { Optimal }\end{array}$ & \\
\hline Auditability & 4 & 10 & 0 & 0 & 0 & 14 \\
\hline Accuracy & 2 & 12 & 0 & 0 & 0 & 14 \\
\hline Completeness & 6 & 8 & 0 & 0 & 0 & 14 \\
\hline Error Tolerance & 4 & 10 & 0 & 0 & 0 & 14 \\
\hline $\begin{array}{l}\text { Execution } \\
\text { Efficiency }\end{array}$ & 4 & 10 & 0 & 0 & 0 & 14 \\
\hline Operability & 7 & 7 & 0 & 0 & 0 & 14 \\
\hline Simplicity & 6 & 8 & 0 & 0 & 0 & 14 \\
\hline Training & 2 & 12 & 0 & 0 & 0 & 14 \\
\hline
\end{tabular}

Berdasarkan deskripsi data dan hasil pengolahan data diatas penulis melakukan analisa deskriptif kualitatif. Dari delapan (8) metrik yang digunakan untuk mengukur optimalisasi prototipe KMS untuk meningkatkan penyuluhan Keluarga Berencana berbasis Android dapat dinyatakan bahwa metrik Operability yang paling optimal karena aplikasi tersebut memiliki user interface yang sederhana sehingga mudah dioperasikan dan digunakan oleh user. Sedangkan metrik yang dianggap paling tidak optimal adalah metrik Accuracy dan Traning dikarenakan belum adanya help yang dapat membantu user dalam mempelajari fasilitasfasilitas menu yang ada di aplikasi prototipe KMS untuk meningkatkan penyuluhan KB pada BP3AKB yang dapat membantu user dalam mempelajari fasilitas-fasilitas menu yang ada dan memenuhi keakuratan sistem dalam penggunaannya.

\section{PENUTUP}

\section{KESIMPULAN}

Dari hasil penelitian yang dilakukan oleh penulis terhadap Penerapan Knowledge Management berbasis android yakni :

1. Pada BP3AKB budaya berbagi pengetahuan sudah berjalan namun kurang efektif. Sebagian besar sharing knowledge di BP3AKB dilakukan dalam bentuk forum diskusi secara tatap muka. Dengan adanya perangkat pendukung knowledge management system dengan diberikan sarana forum diskusi dengan prototipe mobile application sehingga mempercepat 
penyebaran pengetahuan dan pendokumentasian yang baik.

2. Hasil kuesioner terhadap pegawai tentang pra desain aplikasi KMS berbasis android diperoleh hasil dengan nilai 3, 29 dengan kriteria Cukup Baik. Hasil kuesioner terhadap pegawai tentang Pasca desain aplikasi KMS berbasis android diperoleh hasil dengan nilai 4,00 dengan kriteria Baik. Dan Pasca desain aplikasi KMS berbasis android terhadap Kepala bidang memperoleh hasil 3,83 dengan kriteria Baik

3. Hasil kuesioner terhadap pengujian perangkat Lunak dengan metode SQA diperoleh hasil dengan nilai 80,57 dengan Kriteria Optimal. Dari delapan (8) metrik yang digunakan untuk mengukur optimalisasi prototipe KMS untuk meningkatkan penyuluhan Keluarga Berencana berbasis Android dapat dinyatakan bahwa metrik Operability yang paling optimal karena aplikasi tersebut memiliki user interface yang sederhana sehingga mudah dioperasikan dan digunakan oleh user. Sedangkan metrik yang dianggap paling tidak optimal adalah metrik Accuracy dan Traning dikarenakan belum adanya help yang dapat membantu user dalam mempelajari fasilitasfasilitas menu yang ada di aplikasi prototipe KMS untuk meningkatkan penyuluhan KB pada BP3AKB yang dapat membantu user dalam mempelajari fasilitas-fasilitas menu yang ada dan memenuhi keakuratan sistem dalam penggunaannya.

\section{SARAN}

Setelah melihat hasil penelitian yang telah dilakukan, penulis merasa masih banyak kekurangan dan kelemahan dalam KMS berbasis android yang telah diterapkan. Berikut adalah saran-saran dari penulis:

1. Knowledge management system ini perlu dikembangkan lagi untuk dapat terintegrasi dengan unit-unit yang terkait di BP3AKB, agar basis pengetahuan lebih luas dan transfer knowledge yang lebih efektif.

2. Sistem perlu di uji secara berkala dan apabila diperlukan penambahan maupun perbaikan basis pengetahuan pada saat pengembangan perlu diperhatikan tingkat kerumitan akibat banyaknya jumlah pengetahuan yang akan tersimpan pada sistem.

3. Handheld yang dapat digunakan nantinya diharapkan dapat beragam, tidak hanya berbasis sistem operasi Android, melainkan juga yang berbasis Blackberry OS, iOS dan
Windows Phone. Teknologi yang memungkinkan saat ini adalah HTML 5 yang hampir dapat berjalan di semua sistem operasi mobile.

\section{REFERENSI}

[1]. Andy, Randy, Sugiarto, Dedy dan Hetharia, Dorina (2011). Pengembangan dan Penerapan Manajemen Pengetahuan Sebagai Strategi Pendukung Kegiatan Medis Non-Bedah (Studi Kasus Klinik Petukangan Medical Center). ISSN: 1411-6340

[2]. Bommen, Thommy and Bechina, Amtzen (2006). Knowledge Sharing Practices:Analissis of a Globel Scandinavian Consulting Company. ISSN 1479-4411

[3]. Davidson, Carl and Philip Voss (2003). Knowledge Management: An Introduction to creating competitive advantage from intellectual capital. New Delhi: Vision Books.

[4]. Debowski, Shelda (2006). Knowledge Management. Melbourne and Sydney: John Wiley and Son Australia, Ltd.

[5]. Dennis, Alan and Wixom, Haley, Tergaden (2009). Systems Analysis Desagn UML Version 2.0. United States of America: John Wiley \& Sons, Inc

[6]. Fatwan, Satyo dan Alex Denni (2009). Most Admired Knowledge Enterprise (MAKE) Indonesia. Study and Lesson Learned From To Winners. Jakarta : Gramedia

[7]. Ming-Yu Cheng. Knowledge Sharing in Acadmic Institutions : a Study of Multimedia University Malaysia. ISSN 1479-4411.

[8]. Nonaka, Ikujiro and Takeuchi H (1995). The Knowledge Creating 
[9]. Company: How Japanesse Companies Create the Dynamics In Innovatio. Oxford University Press.

[10]. Rahmayu, Mulia (2013). Prototipe Knowledge Management System Untuk Meningkatkan Proses Belajar Grammar Berbasis Smartphone Android:Studi Kasus Lembaga Bimbingan Belajar Primagama Jakarta. Jakarta : Pasca Sarjana Nusa Mandiri

[11]. Safaat, Nazruddin (2012). Pemrograman Aplikasi Mobile Smartphone dan Tablet PC Berbasis Android. Bandung : Informatika.

[12]. Sanggono Yudhianto, Agus dan Kartawijaya, Richard. 2008. Penerapan Knowledge Management PT. Astra Graphia Tbk. Jakarta : Jurnal Piranti Warta. ISSN 1411-2221.

[13]. Setiarso, Bambang, Nazir Harjanto, Tritono, dan Hendro Subagyo (2009). Penerapan Knowledge Managent Pada Organisasi. Edisi 1. Cetakan Pertama. Yogyakarta : Graha IImu.

[14]. Subagja Sambas. (2011). Perancangan Knowledge Manajement System Untuk Pelaanan Perizinan Terpadu Satu Pintu. Konferensi Teknologi Informasi dan Komunikasi Untuk Indonesia. 14-15 Juni 2011. Bandung

[15]. Sudjana (2002). Metode Statistika. Bandung: PT. Tarsito.

[16]. Sugiyono (2009). Staristika Untuk Penelitian. Bandung :alfa Beta.

[17]. Rosa, M. Shalahuddin (2011). Modul Pembelajaran Rekayasa Perangkat Lunak. Bandung : Modula

[18]. Tiwana, Amrit. (2000). The Knowledge Management Tollkit, IT, Atrategy and Knowledge Platform. Second Edition. New York : Prentice Hall PTR, Upper Saddler River

[19]. Thohari, Afandi Nur Aziz, Santoto, Imam Kodrat, dan Martono, Kurniawan
Teguh. (2013). Pembuatan Aplikasi Mobile Learning Sebagai Sarana Pembelajaran Di Lingkungan Universitas Diponegoro. Jurnal Teknologi dan Sistem Komputer. Vol 1 No. 2 April 2013.

[20]. Wahono, Romi Satrio (2003). Kuliah Umum IlmuKomputer.Com. Jakarta: IlmuKomputer.Com. 